Supporting Information

\title{
Selective Production of Oxygen from Seawater by Oxidic Metallate Catalysts
}

\author{
Thomas P. Keane and Daniel G. Nocera*
}

Department of Chemistry and Chemical Biology, Harvard University, 12 Oxford Street, Cambridge, MA 02138, United States

*dnocera@fas.harvard.edu 


\section{Table of Contents}

$\begin{array}{ll}\text { NaClO Calibration Curves } & \text { S3-S4 }\end{array}$

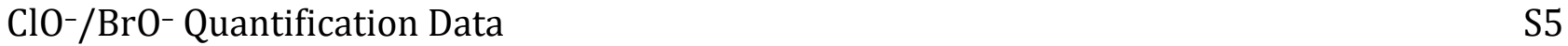

Faradaic efficiency yields for hypochlorite/hypobromite production S6 


\section{NaClO Calibration Curves}

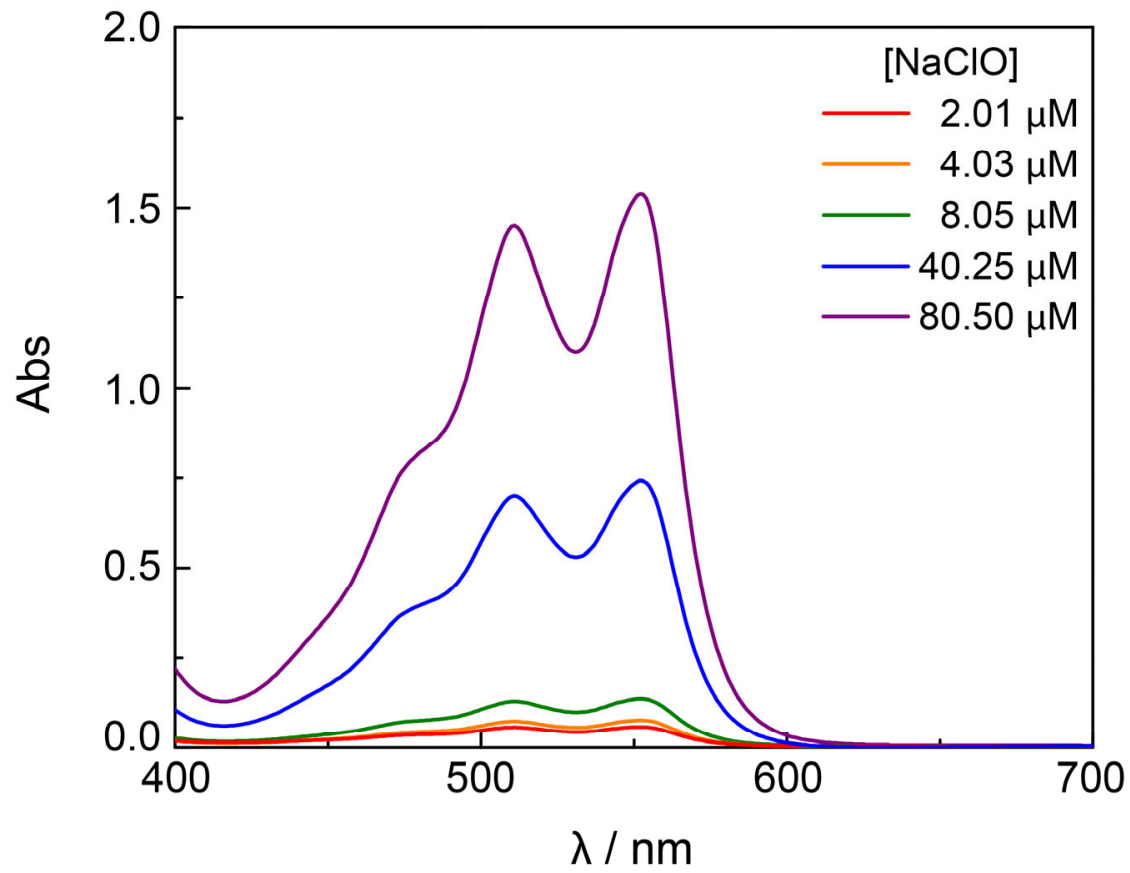

Figure S1. Spectra used to construct DPD calibration curve for solutions buffered with 0.1 $\mathrm{M} \mathrm{KP}, \mathrm{pH} 7$.

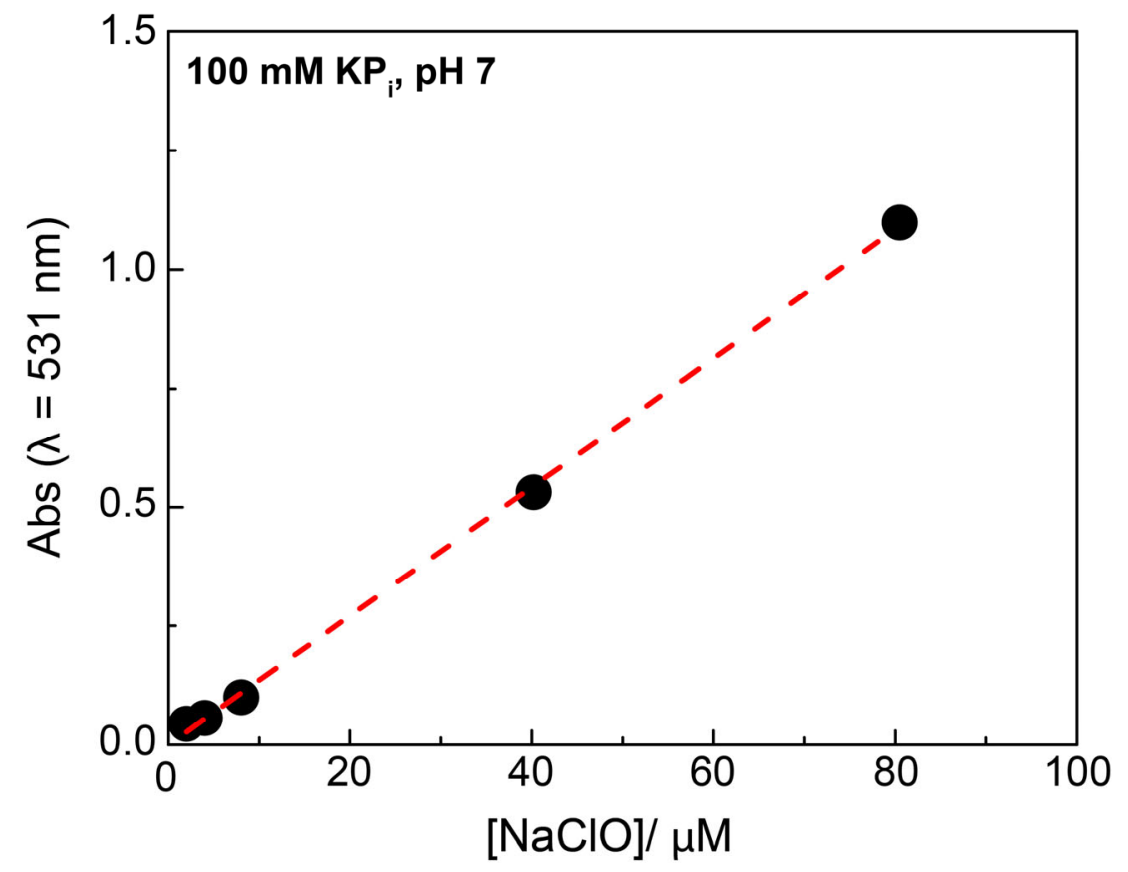

Figure S2. DPD calibration curve for solutions buffered with $0.1 \mathrm{M} \mathrm{KP}_{\mathrm{i}}, \mathrm{pH} 7$. 


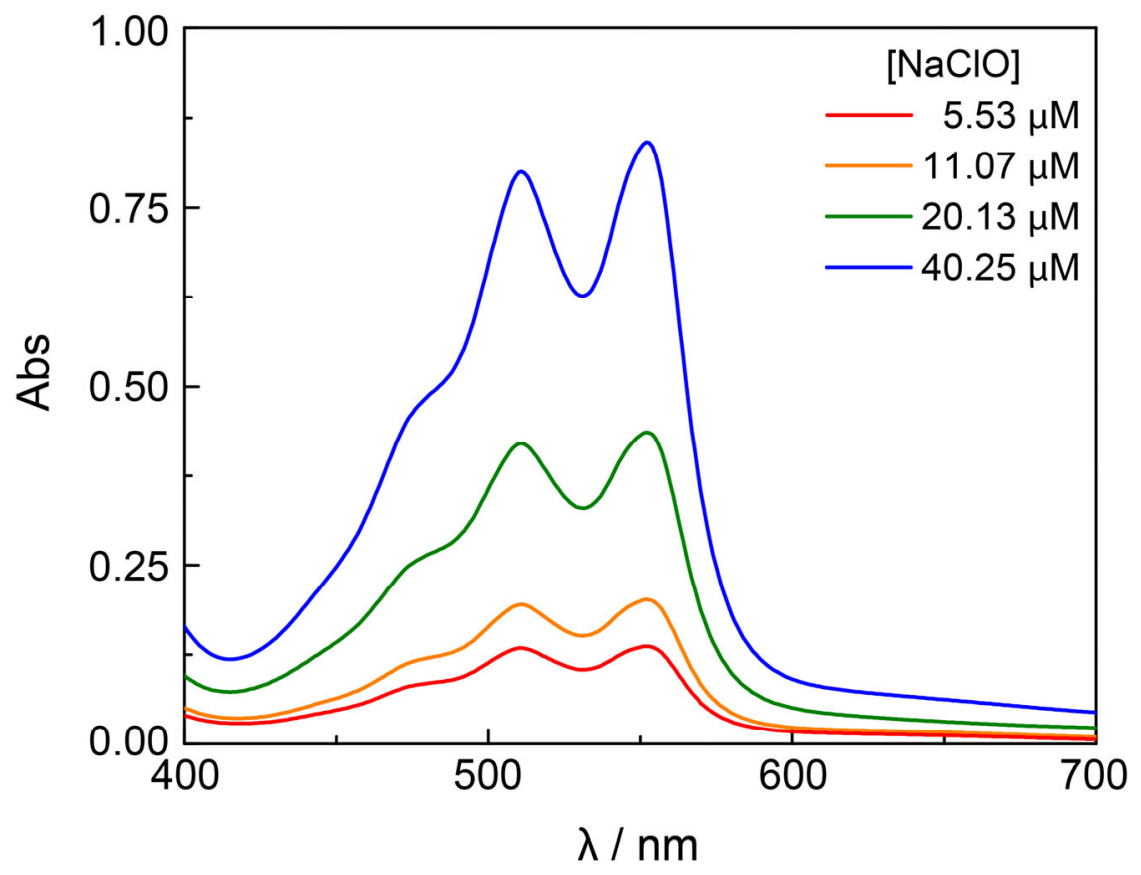

Figure S3. Spectra used to construct DPD calibration curve for solutions buffered with 0.1 $\mathrm{M} \mathrm{KB}$, $\mathrm{pH} 9.2$.

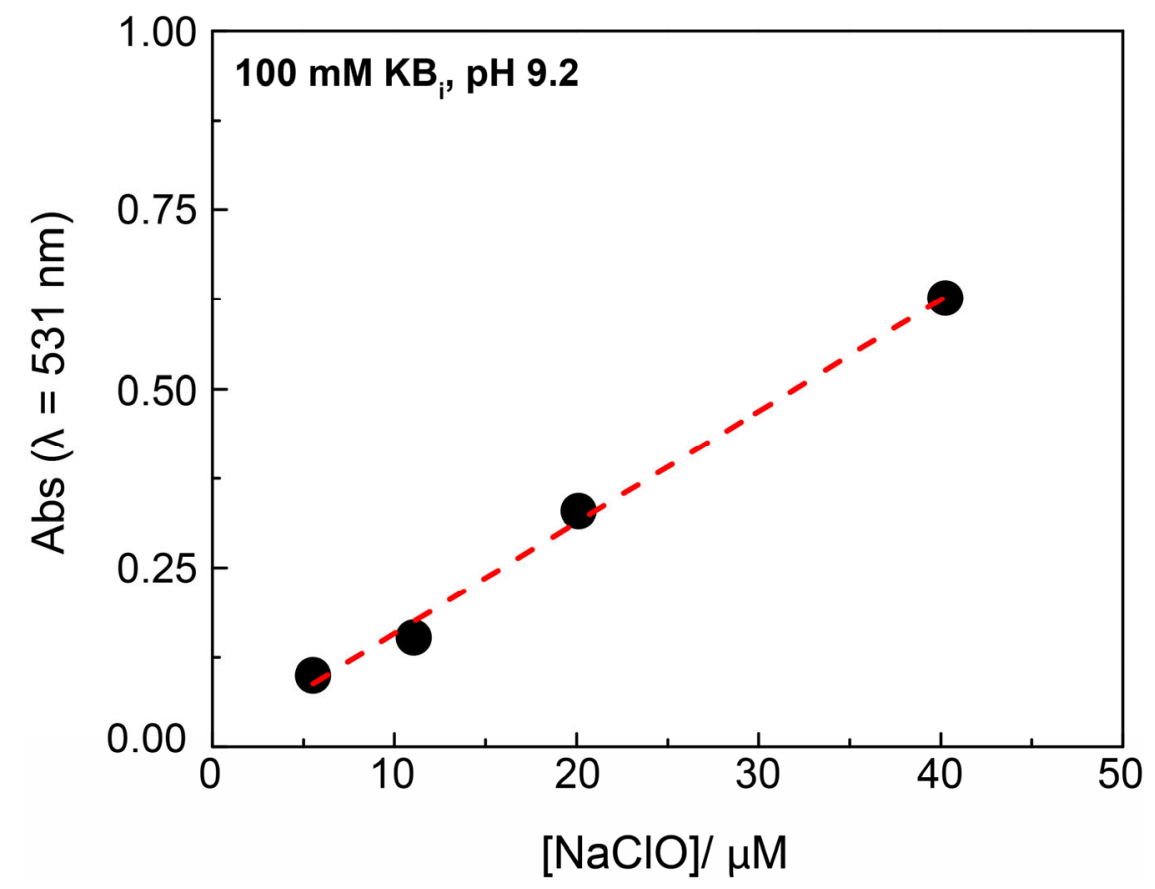

Figure S4. DPD calibration curve for solutions buffered with $0.1 \mathrm{M} \mathrm{KB}, \mathrm{pH} 9.2$. 


\section{ClO-/BrO- Quantification Data}

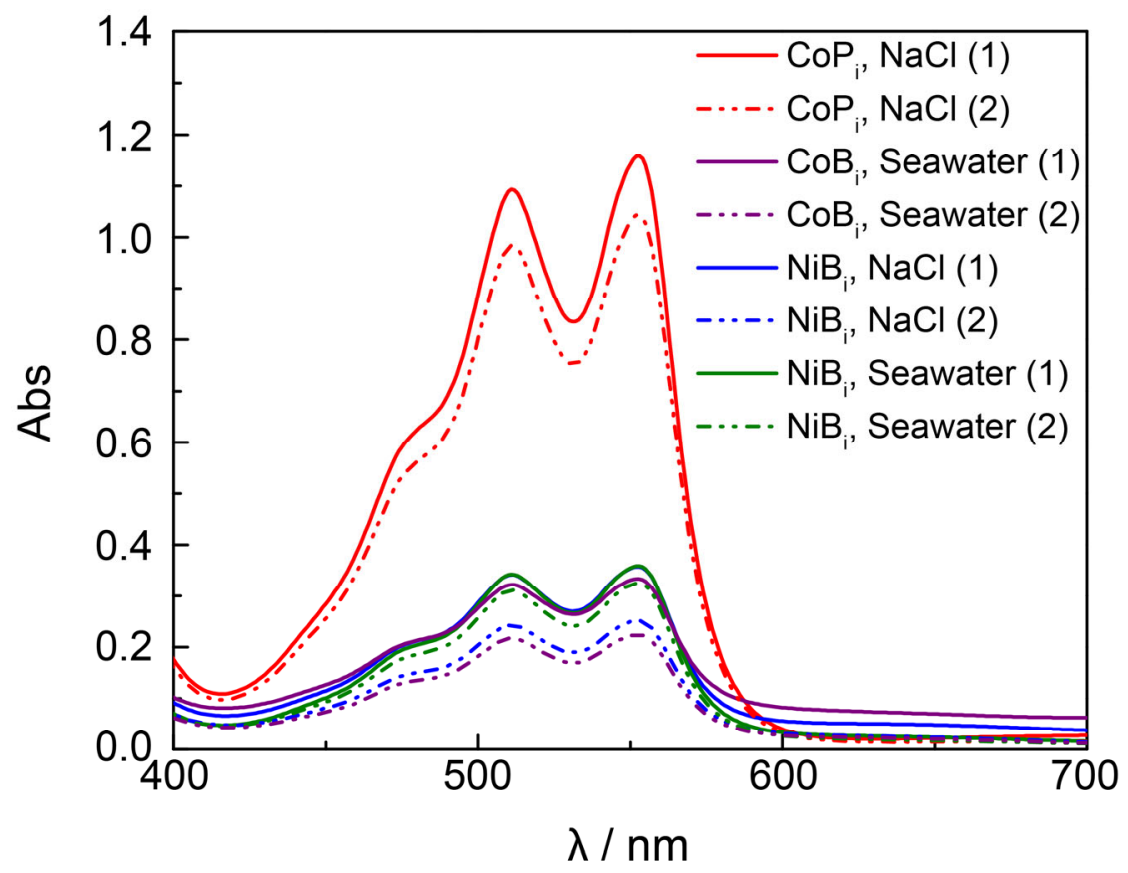

Figure S5. Spectra used to determine the concentration of $\mathrm{ClO}^{-} / \mathrm{BrO}^{-}$produced during each electrolysis. 
Table S1. Data used to calculate faradaic efficiency of hypochlorite (ClO-) and hypobromite (BrO-)

\begin{tabular}{|c|c|c|c|c|c|c|}
\hline Catalyst & Electrolyte & Trial \# & $\begin{array}{c}\text { Charge } \\
\text { Passed(C) }\end{array}$ & $\mathrm{V}_{\text {cell }}(\mathrm{mL})$ & $\begin{array}{c}\text { Abs } \\
(\lambda=531 \mathrm{~nm})\end{array}$ & $\begin{array}{c}\text { FEclo-/Bro- } \\
(\%)\end{array}$ \\
\hline \multirow{2}{*}{$\mathrm{CoP}_{\mathrm{i}}$} & \multirow{2}{*}{$\begin{array}{l}0.1 \mathrm{M} \mathrm{KP} \text { i } 0.5 \mathrm{M} \\
\mathrm{NaCl}, \mathrm{pH} 7\end{array}$} & 1 & 14.9 & 50 & 0.835 & 4.0 \\
\hline & & 2 & 17.9 & 40 & 0.753 & 2.4 \\
\hline \multirow{2}{*}{$\mathrm{CoB}_{\mathrm{i}}$} & \multirow{2}{*}{$\begin{array}{c}0.1 \mathrm{M} \mathrm{KB}_{\mathrm{i}} \text { in } \\
\text { Seawater, pH } 9.2\end{array}$} & 1 & 6.6 & 35 & 0.270 & 1.8 \\
\hline & & 2 & 11.5 & 50 & 0.190 & 1.0 \\
\hline \multirow{2}{*}{$\mathrm{NiB}_{\mathrm{i}}$} & \multirow{2}{*}{$\begin{array}{c}0.1 \mathrm{M} \mathrm{KB}_{\mathrm{i}} 0.5 \mathrm{M} \\
\mathrm{NaCl}, \mathrm{pH} 9.2\end{array}$} & 1 & 35.0 & 35 & 0.266 & 0.33 \\
\hline & & 2 & 28.9 & 50 & 0.241 & 0.51 \\
\hline \multirow{2}{*}{$\mathrm{NiB}_{\mathrm{i}}$} & \multirow{2}{*}{$\begin{array}{c}0.1 \mathrm{M} \mathrm{KB} \text { in } \\
\text { Seawater, pH } 9.2\end{array}$} & 1 & 2.7 & 35 & 0.264 & 4.2 \\
\hline & & 2 & 2.4 & 50 & 0.170 & 4.3 \\
\hline
\end{tabular}

